\title{
Exacerbados. Identidades académicas y la transformación de la educación superior chilena
}

\author{
Exacerbated. Academic Identities and the Transformation of Chilean Higher \\ Education
}

\author{
Carla Fardella Cisternas \\ Universidad Andrés Bello \\ Álvaro Soto Roy \\ Universidad Alberto Hurtado
}

\author{
Javiera García-Meneses \\ Pontificia Universidad Católica de Valparaíso
}

Alejandra Corvalán-Navia

Universidad Andrés Bello

\section{Resumen}

La diversificación de fuentes de financiamiento, instalación de la cultura de accountability y medidas para maximizar la eficacia de diferentes procesos académicos son expresiones de una educación superior en transformación, que precisa de la estratégica reorganización de su fuerza laboral académica. La gestión universitaria ha concretado estos cambios en nuevas formas de concebir, medir e incentivar el trabajo académico. La nueva gestión dispone al cuerpo académico a la construcción y apropiación de nuevas identidades laborales; no obstante, éstas no son asumidas por los/as trabajadores/as sin conflicto. A partir del análisis de 40 entrevistas a académicos/as, se reportan los hallazgos en 3 categorías, a saber: narrativas identitarias del académico/a crítico/a, narrativas identitarias del académico/a solitario/a y narrativas identitarias del académico/a prestigioso/a. Como discusión se expone como estas narrativas convergen y exacerban, dadas las transformaciones de la educación superior.

Palabras clave: Instrumentos para la Gestión de la Actividad Científica; Educación Superior; Identidad académica; Gestión universitaria

\begin{abstract}
The diversification of funding sources, the installation of the accountability culture and measures to maximize the effectiveness of different academic processes are expressions of higher education in transformation, which requires the strategic reorganization of its academic workforce. University management has materialized these changes in new ways of conceiving, measuring and encouraging academic work. University management has materialized these changes in new ways of conceiving, measuring and encouraging academic work. Based on the analysis of 40 interviews with academics, the present paper reports the findings in 3 categories, namely: identity narratives of the critical academic, identity narratives of the solitary academic and identity narratives of the prestigious academic.
\end{abstract}

Keywords: Instruments for Management of Scientific Activity ; Education, Higher ; Academic identity; University management 


\section{INTRODUCCIÓN}

La reorganización de la universidad ha implicado profundas transformaciones movilizadas por nuevas lógicas de gestión pública, basadas en la diversificación del financiamiento, la regulación del mercado, la cultura del accountability, los mecanismos de acreditación y el aseguramiento de calidad (Anderson, 2008; Bernasconi, 2010; Slaughter y Rhodes, 2004). Este contexto ha puesto en jaque los mecanismos tradicionales de organización universitaria (Altbach, 2000; Altbach y Salmi, 2011; OCDE/CEPAL/CAF, 2013), reconfigurándolos como organizaciones flexibles y orientadas al rendimiento. Esto ejerce indudable influencia en la concepción de trabajo y trabajador académico (Brunner, 2008), poniendo en tensión las identidades laborales tradicionales del cuerpo académico.

Este trabajo expone los relatos de académicas y académicos en torno a su trabajo e identifica las controversias para dar cuenta de sí en un proceso de transformación de la educación superior. Para ello, se reportan los resultados de un análisis discursivo pragmático (Potter, 1998; Potter y Wetherell, 1987; Wetherell y Potter, 1998) de 40 entrevistas a académicos/as de planta de universidades tradicionales de la zona central del país.

Los resultados evidencian la coexistencia de 3 narrativas identitarias en respuesta a la reorganización universitaria. La primera, es heredera de las identidades académicas tradicionales y despliega una posición crítica frente a las prácticas dominantes de las nuevas formas gestión universitaria, poniendo énfasis en la transformación social y la docencia como acciones distintivas de la academia. La segunda, proyecta una imagen de académico/a como figura central de su escena laboral, forjando un yo resplandeciente que opaca el contexto institucional. Finalmente, la tercera, entreteje la representación del académico/a prestigioso/a, agrupando narraciones que buscan diferenciar al hablante de sus pares a través de la distinción y la acreditación de su mérito.

\section{TRANSFORMACIONES EN LA EDUCACIÓN SUPERIOR CHILENA Y LA ACADEMIA}

La reforma económica neoliberal chilena iniciada a fines de la década de 1970, junto con los procesos de modernización político-cultural ocurridos desde el retorno a la democracia, han implicado el socavamiento de la matriz estadocéntrica, consolidado un nuevo modelo de desarrollo capitalista -global, informacional, flexible y en red- (Stecher, 2014). Estas alteraciones socioeconómicas y tecnológicas han demandado una reestructuración de la educación superior (ES) y la actividad académica. Se han instalado una serie de re-

${ }^{1}$ Las universidades tradicionales son aquellas que integran el Consejo de Rectores de las Universidades Chilenas y en total suman 30 universidades, 18 públicas y 12 particulares. 
formas de ES inspiradas en la lógica del New Public Management (NPM) (Anderson, 2008; Bernasconi, 2010; Slaughter y Rhodes, 2004), que incorpora actores y principios propios del mundo privado tales como flexibilización, tercerización y reducción dotacional (Bejerot y Hasselbladh, 2013; Hood, 1991). El NPM en las organizaciones universitarias se ha despegado en torno a diversos instrumentos de acreditación y medidas de maximización-optimización de diversos procesos productivos (Brunner y Villalobos, 2014; Gill, 2009). Cada universidad busca responder a estas medidas introduciendo nuevas regulaciones y prácticas de gestión del trabajo académico (Bernasconi, 2015), tales como incentivos a publicaciones indexadas, evaluaciones de calidad, sistemas de acreditación, de registro e índices de monitoreo (Fardella et al., 2017). Pese a que estos cambios presentan especial atención a la reorganización del trabajo de los y las académicas (Altbach y Salmi, 2011), la reorganización de la fuerza laboral académica un campo poco explorado.

\section{LA IDENTIDAD Y EL OFICIO ACADÉMICO}

Un eje relevante para comprender de la reorganización del trabajo académico es la identidad de sus trabajadores/as (Araujo y Martuccelli, 2010; Soto, 2008), entendida como producciones simbólicas articuladas narrativamente, centradas en la propia historia laboral, que dotan de continuidad y sentido a la experiencia, asignando significados a otros/as y a sí mismo/a, en tanto actor singular al interior de ese espacio sociolaboral (Soto, et al., 2017).

La identidad moviliza saberes e imaginarios compartidos cotidianamente en un grupo específico, situado histórica y materialmente. En un entorno en transformación, la identidad está también en constante reestructuración y, más que relatos uniformes, manifiesta recurrencias narrativas, ya sea ideales, dinámicas de pertenencia y diferenciación, o juicios éticos para evaluar u orientar las decisiones (Dubar y Tripier, 1998). La construcción identitaria moviliza referentes simbólicos disponibles en el entorno sociolaboral, combinando viejas y nuevas narrativas, según las condiciones de la experiencia (Watson, 2009), ofreciendo sentido, situando y legitimando la acción (Potter y Wetherell, 1987). Las narrativas identitarias no necesariamente son coherentes entre sí, pero que pueden sucederse o alternarse, ajustándose a la particularidad de la experiencia laboral.

Este dinamismo es posible de observar en la identidad académica, una forma de identidad de oficio. Las identidades tradicionales de oficio se basaban en un cuerpo de conocimientos experto, la autonomía técnica del grupo, y la orientación normativa hacia el servicio a otros/as y un estatus social particular (Ahlbäck Öberg et al., 2016; Evetts, 2011; Gorman, 2014). Siguiendo a Harry 
Braverman (1984) y Alfredo Hualde (2000), esos pilares se ven transformados con las reformas del NPM, principalmente por la reducción de la autonomía y del control en sus conocimientos, entendido como un proceso de desprofesionalización (Gorman, 2014). En términos de identidades laborales, desde formas colectivas y estables de identificación se deriva a colectivos múltiples, variables y efímeros, que entregan recursos de identificación gestionados de manera individual, diversa y provisoria (Dubar, 2000).

En el plano académico, las identidades laborales enfrentan nuevas interpelaciones, entre nuevos discursos sobre el sentido de la actividad y nuevas formas de interacción con la universidad y estudiantes. El oficio académico ve transformados sus espacios de autonomía y amenazadas sus competencias. Michael Gibbons y sus colaboradores (1994) sostienen que los académicos han ido perdiendo su condición de artesanos/as autónomos/as del saber, para conformarse paulatinamente en engranajes de una maquinaria mayor de producción del conocimiento, muy en la línea de la desprofesionalización académica (Trow, 1993) o del gremio académico proletarizado (Wilson, 1991).

El nuevo modelo de gestión universitaria despliega instrumentos de evaluación, estandarización, jerarquización e incentivos, nuevas grillas y criterios para distinguir el éxito y la excelencia (Fardella et al., 2017). Las nuevas imágenes propuestas a las de académicos/as enfatizan su compromiso con la búsqueda de fondos de investigación, centrados en emprendimientos e innovaciones, permanentemente al servicio de estudiantes e implicados en los sistemas de evaluación, ranking y acreditación (Ainsworth y Hardy, 2008). La nueva educación superior requiere un cuerpo académico óptimo en investigación, gestión, innovación, difusión y vinculación con el medio, que compita por número de publicaciones, gestione grandes matrículas, satisfaga a estudiantes, busque nuevos/as clientes/as y se posicione con liderazgo en redes académicas internacionales (Clarke et al., 2012; Gill, 2009; Harding et al., 2010; Worthington y Hodgson, 2005).

De esta manera, las nuevas formas de gestión del trabajo académico se enfrentan a formas tradicionales de identidades académicas, probablemente aún vigentes, centradas en la reputación entre pares y en rechazo al monitoreo y la estandarización. Robert Merton (1968) señala que el/la académico/a históricamente ha buscado estatus en las relaciones con estudiantes y con pares. A más de cinco décadas de sus estudios, la autonomía sigue siendo pilar de la identidad académica y, en las descripciones de sí hechas por académicos/as, se afirma que la creación de conocimiento requiere de libertad y autonomía (Fardella et al., 2015). Es posible plantear que la actividad académica, reorganizada y reordenada en torno a nuevas metas e indicadores propios de una universidad 
managerial, desafía y tensiona un conjunto de sentidos que la academia ha construido históricamente para su trabajo.

Este artículo se pregunta cómo las nuevas prácticas de gestión se enfrentan o complementan con las significaciones tradicionales del trabajo académico. Sin la pretensión de encontrar formas puras de adhesión o resistencia al nuevo modelo de gestión universitaria, el interés está en ver cómo los flujos de significados se combinan en las construcciones identitarias de académicos/as, comprendiendo convergencias y divergencias identitarias que se construyen en las narraciones de académicos/as en un contexto de managerialización de la Universidad.

\section{MÉTODO}

Los resultados expuestos son parte de un estudio cualitativo (Flick, 2004) realizado entre los años 2016-2018. La producción de datos consta de 40 entrevistas activas a académicos de planta pertenecientes a diversas áreas del conocimiento (ingeniería, química, medicina, psicología, sociología, trabajo social, arquitectura, historia, literatura y pedagogía) de 13 diferentes universidades chilenas privadas y estatales. Adicionalmente, procuramos igual representación de varones, mujeres y diversidad en años de ejercicio laboral. En las entrevistas activas (Denzin, 2001; Holstein y Gubrium, 1995), los/as participantes (entrevistador/a y entrevistado/a) son asumidos como sujetos/as que interactúan abiertamente, guiados temáticamente por una pauta flexible para aproximarnos a las narraciones espontáneas a través de las cuales los/as académicos/as dan cuenta de sí, en este particular contexto de transformación.

El análisis de datos se realizó en dos etapas. Primeramente, el corpus de datos se codificó en función del contenido. A partir de ello, creamos unidades de significado, filtradas y reorganizadas a partir de los objetivos de la investigación. Tras la lectura sistemática de los códigos y su contexto, se buscaron patrones, temas y regularidades, así como contrastes, paradojas e irregularidades (Atkinson y Coffey, 2003). En segundo lugar, se procedió a agrupar los códigos en categorías analíticas que dieran cuenta de los ejes narrativos organizadores de la identidad. Para ello, se siguió la orientación del análisis discursivo de narrativas identitarias (Sisto y Fardella, 2009; Wetherell, 2007).

\section{RESULTADOS}

Las narrativas que exponemos a continuación muestran el complejo tejido que compone la identidad académica en un contexto de managerialización de la Universidad, a la vez muestra los anclajes del modelo managerial en el trabajo 
de narrarse como académico/a en estos tiempos. Las narrativas identitarias que presentamos no representan a ningún académico/a, o área del conocimiento en particular, ni tampoco corresponden a una tipología de las identidades académicas. Más bien se trata de guiones, que coexisten y se combinan entre sí transversalmente a todas las entrevistas. En ocasiones pueden ser incoherentes entre sí: relatos oposicionistas y divergentes frente a las actuales prácticas de gestión universitarias y al mismo tiempo relatos que parecen converger con relativa docilidad. Justamente esto es la evidencia de las tensiones y contradicciones de los procesos de construcción identitaria en los académicos en la universidad actual. La exposición de dichas narrativas se ilustrará utilizando fragmentos representativos del corpus total y posteriormente en las discusiones profundizamos en los matices, encuentros y desencuentros de estas 3 narrativas.

\section{Narrativas identitarias del académico/a crítico/a}

Bajo las narrativas identitarias del académico/a crítico/a agrupamos aquellos relatos que, mediante el desarrollo de contenidos heterodoxos a los ideales de la universidad actual, permite a los/as entrevistados/as dar cuenta de sí diferenciándose de los mandatos managerialistas. Aparece predominantemente la figura de un académico/a comprometido/a con la transformación social y la participación en el espacio público, relatos anclados en una universidad tradicional construida en oposición a los modelos de gestión universitaria actual (Bernasconi, 2010; Gill, 2009). La narrativa identitaria critica porta demandas éticas para los/as mismos académicos/as y juega a socavar los ideales que la universidad managerial dibuja. La pasión, la vocación y el compromiso social aparecen como componentes centrales de sentido al trabajo y, al mismo tiempo, son precisamente el contrapunto de divergencia para oponerse al modelo actual de universidad.

Un primer aspecto de estas narrativas criticas es presentarse a sí mismo/a como disconforme con el modelo promovido por la nueva gestión universitaria. El entorno se representa como un sistema amenazante y con un efecto perverso sobre la academia: "Están extinguiendo el trabajo científico" (Entrevistado 3, entrevista personal, marzo de 2018).

Se observa una disidencia con el modo de organizar el trabajo académico. La descripción negativa del modelo de gestión instalado tiene el particular efecto para el/la hablante de dislocar la imagen de sí en el espacio y así construir discursivamente una posición de exterioridad respecto de los cambios, instalándose en un lugar ajeno y simultáneamente mostrando una distancia evaluadora, donde se constituye en un/a sujeto/a crítico/a de su entorno. 
La narrativa del académico/a crítico/a o disidente se refuerza mediante la definición de su trabajo como una actividad altamente comprometida con lo social, siendo central en la disidencia el sentido social asignado por las y los entrevistados al trabajo científico:

Mi percepción de la universidad está cambiando un poco. Yo vivía la universidad como:: (.) un espacio de transformación social, no (?), pero hoy día la universidad como:, lo pienso un espacio fundamental para la reproducción y la acumulación del capital. (Entrevistado 25, entrevista personal, enero de 2019)

Tal descripción del trabajo científico permite la presentación de un self académico comprometido e involucrado con la sociedad y su transformación, a partir del conocimiento que produce, es decir, en función de su actividad profesional (Fardella, et al., 2015; 2017). En este sentido, las entrevistas muestran que la participación en el espacio público, la implicancia del trabajador/a con el progreso y la transformación de su entorno constituyen la naturaleza ética de la labor, dotando de sentido sus tareas y diferentes procesos en el trabajo:

Uno trabaja por un un: un afán transformador del sistema escolar, en el caso de educación (...) mucho de lo que nos moviliza es (.) hacer doctora:do, hacer investigación, representar a la universidad en mi:les de luga:res (.) es una mane:ra que tenemos de participar de la discusión de la política pú:blica, es una manera que tenemos de (.) ingerir, decir que estos te:mas para nosotros son temas relevantes y que vamos a salir a discutirlos en la pla:za pública, con más o menos impacto, pero sí participar de esos debates. (Entrevistada 10, entrevista personal, octubre de 2018)

El segundo componente de esta narrativa es la narrativa de la vocación social como sustento del compromiso social y crítico antes señalado. La vocación es un elemento crucial para dar cuenta de sí, en tanto se trata de una disposición "interna", es decir, una cualidad personal que reflejaría los aspectos íntimos del hablante: "hay una cuestión de vocación como de gusto personal, digamos. Yo aquí me siento como pez en el agua, me encanta la labor académica" (Entrevistado 5, entrevista personal, octubre de 2018). Tal como se ilustra en el fragmento, la vocación, aparece discursivamente como una disposición interna hacia algo externo y posee la potencia simbólica de ilustrar prístinamente algo del hablante, como si fuera reflejo "auténtico" de su interior. Así, el compromiso social construido discursivamente como vocación funciona como sustento y referente ético para desarrollar el oficio académico:

Yo creo primero, hay (.) maneras distintas de entender tu: tu, filiación con el traba:jo no (?), yo creo que hay personas que construyen itinerarios más individua:les, más centrados en su pe:ga, que ojalá no los molesten porque lo importante es su te:ma, y se construyen desde ahí: y yo creo que hay 
otras mane:ras, otros desempeños que son más (.) comunita:rios, instituciona:les. (Entrevistada 9, entrevista personal, octubre de 2018)

La primacía de este elemento sobre otros aspectos identitarios alineará deberes, creencias y sentidos respecto de sus tareas, forjará criterios razones para permanecer, invertir o desistir de determinados proyectos, pero también para justificar o desvalorizar las trayectorias de pares en la academia. De ahí que la vocación es construida como elemento canónico e indiscutible de las narrativas de la identidad académica.

Profundizando en este componente, la vocación y el compromiso son usados como aspectos que caracteriza a un grupo de académicos/as: "yo creo que hay otras mane:ras, otros desempeños que son más (.) comunita:rios, instituciona:les". Este fragmento es interesante, el compromiso social se construye en oposición al compromiso con el proyecto personal; motivación por la participación y el debate social en contraposición al incentivo individual y al beneficio personal. Esta distinción establece una diferencia entre un perfil académico tradicional y uno centrado en la productividad individual. Cabe señalar que el compromiso social forma parte esencial de la imagen de sí y esta construcción se realiza desde una base colectiva.

Los relatos buscan, mediante la caracterización de prácticas específicas de su trabajo académico, demostrar la implicación con la realidad social (por ejemplo, la docencia de pregrado), con la vinculación con el medio y con la valoración de la posición laboral como espacio estratégico para modificar sentidos, prácticas y políticas de la vida social. La vocación social, en tanto núcleo ordenador de la identidad, retoma algunos elementos identitarios de la figura del trabajador/a del Estado, que se reiteraría en la organización de la universidad pública napoleónica.

Esta imagen se vincula, simultáneamente, con una serie de objetivos e ideales que marcarán un código de conducta, una gramática que consigue dibujar un/a trabajador/a deseable, leal al ethos académico tradicional, y otro/a que no. Todo ello conforma una ética que busca establecer patrones apropiados de actuar y sobre todo de ser.

Cuando yo llegué los más jóvenes en particular alegaban porque eran muy pocos los incentivos (...). Entonces ((eh::)) no es una valorización de la producción sino lo que voy a ganar. Ahora, no digo que sean todos así, hay gente muy valiosa en la facultad donde yo trabajo que estoy segura, que producen (.) no por el dinero, producen porque a ellos les interesa el deba::te. (Entrevistado 25, entrevista personal, enero de 2018) 
El fragmento permite ilustrar cómo, a través de la construcción de un antagonista, aquel que trabaja persiguiendo sus intereses personales se reafirma un modo correcto de ser académico/a. De acuerdo con el texto, el debate social aparece contrapuesto a otros modos de producción de científica, a la vez que mediado por otras motivaciones. El propósito transformador del trabajo académico sería el principio ordenador que da sentido a las otras tareas, el criterio demarcador que establece una prioridad ontológica en tanto existe una categoría particular de personas que tienen mayor valor. Se trata de atributos que se organizan discursivamente como una ética específica del deber ser académico/a y al mismo tiempo como valor contrapuesto a la ética empresarial o ética utilitaria de la auto-optimización (Du Gay, 2007). Mediante este tipo de descripciones de sí, las y los entrevistados pueden construir una distancia crítica y ética respecto del modelo normativo de desempeño académico y resaltar su compromiso con la transformación y progreso social.

\section{Narrativas identitarias del académico/a solitario/a}

La segunda narrativa identitaria agrupa relatos que tienen la facultad de construir al hablante como una figura central de su escenario laboral. De estas narrativas se desprende una identidad resplandeciente que opaca las instituciones y al mismo tiempo solitaria en tanto invisibiliza los vínculos a la base del trabajo académico. Por ello, la casa de estudio, las y los colegas, estudiantes, las editoriales y la disciplina aparecen en los relatos como simples telones de fondo para la ejecución de una performance académica atomizada.

Un primer componente de esta narrativa es la construcción de la universidad y sus demandas como un escenario donde se despliega el yo académico. Para explicara esto puede resultar ilustrador comparar las narrativas identitarias académicas con narrativas de otros/as trabajadores/as. Usualmente, en otros sectores productivos, las tareas y responsabilidades son narradas como una obligación propia de la cultura del trabajo. Por el contrario, en el caso de la academia, el material revisado tiende a construir las actividades laborales como un conjunto de tareas que no están exigidas ni determinadas por el contexto, sino fruto de la vocación y motivación del hablante. Es decir, académicos/as describen su labor más bien como productos y representaciones de sus intereses personales y en términos más generales de su vocación.

Durante mi posdoc, ponte tú, yo había hecho mi proyecto FONDECYT. Había adelantado un montón de cuestiones, había escrito mis artículos, todos mis otros compromi:sos, son además (.) cosas que yo quería hacer porque a mí me gu:sta la academia, o sea no estoy pa acredita:r cachay no: no: no pedí la pega [(.) pa trabajar en acreditación cachay ((risas))]. (Entrevistada 8, entrevista personal, mayo de 2018) 
En el fragmento expuesto, el hablante aclara cómo sus obligaciones laborales "son además cosas que quería hacer". En este enunciado el trabajo, más que como un deber, es descrito como una actividad que concuerda con sus gustos. Coherente con esto, el trabajo aparece como un instrumento mediante el cual académico/a puede expresar las propias motivaciones: "Entonces para mí en realidad ser académico es hacer lo que me gusta, y si bien es un trabajo, como es lo que me gusta, la verdad que no es una carga" (Entrevistada 12, entrevista personal, noviembre 2018), "me están pagando por lo que me gusta, sería terrible que me pagaran por lo que no me gusta" (Entrevistada 10, entrevista personal, octubre 2018). Incluso, de manera más radical, en algunas ocasiones la actividad laboral, al confluir con los gustos personales, emerge como una fuente de goce "la investigación a mí me da mucho placer" (Entrevistado 9, entrevista personal, septiembre 2017). De esta manera, las demandas propias del contexto laboral universitario son reinterpretadas y narradas por los/as académicos/as como actividades autoimpuestas, fruto de sus intereses personales, invisibilizando y desconociendo la agencia de los entornos laborales.

En esta misma línea encontramos relatos que tienen la función de construir al hablante en una figura autónoma e independiente de su entorno. Y, si bien las maneras de construir esta imagen de sí son diversas en contenidos, confluyen en relatar la imagen autónoma y autorregulada del académico/a. Esto se evidencia, por ejemplo en los fragmentos anteriores donde vemos al hablante, describiendo su trabajo y dando realce a su capacidad para definir cuáles son y no son sus tareas dentro de la universidad ("o sea no estoy pa acredita:r cachay no: no: no pedí la pega (.) pa trabajar en acreditación cachay"). El/la hablante se muestra como un/a trabajador/a que decide cuál es su función en el escenario laboral y los criterios para decidir son una expresión de sí y no las demandas institucionales o de base colectiva. Tal como señala Álvaro Soto y Tomás Gaete (2013), se trata de un tipo de narraciones identitarias que se ordenan en torno a la demostración de "múltiples competencias que los sujetos sienten que despliegan de manera autónoma y cotidianamente en el trabajo, de hecho les permite expresar sus rasgos, creencias y valores más sustantivos" (p. 1172).

Efectivamente, se trata de narraciones que tienen el efecto pragmático de situar dentro de la persona el lugar donde se toman las decisiones y resuelven problemas, además de los criterios mediante los cuales se solucionan. Las narraciones dan cuenta de un/a trabajador/a que actúa impulsado por sus intenciones, cogniciones e intereses, situando dentro de sí la fuente de donde emana la capacidad y la fuerza de actuar. En particular, la academia concordaría sobre todo con los intereses, las preferencias y lo deseado como expresión singular de la individualidad del hablante. De allí que el self-académico emerge 
como el principal referente para decidir, como una interioridad para complacer.

Esta manera de construir el yo académico deriva de un proceso particularmente interesante del hablante con su entorno. La exaltación de yo es consecuencia de reiteradas omisiones del contexto o aspectos de este, tales como sus demandas, su organización, su funcionamiento o sus límites.

B: (Eh::) (3) Creo que es una: (.) no sé cómo decirlo. Yo publico bastante (.) en revista indexa:das y no indexadas. (Eh:) (.) por lo tanto yo no me (.) yo de manera personal no me he visto: eh:: Afectado negativamente (.) por el sistema. No: No: o sea porque hay revistas indexadas que me interesan, pero hay otras que no. Yo publiqué por ejemplo en la revista alfa que es una mie:rda de revista, no (?), pero es indexada. ¿por qué es una mierda de revista (?), porque es una revista que no tiene ningun:a política editorial, no (?), es una revista transdisciplina:ria (.) que yo jamás en mi vida compraría.

A: Y porqué publicaste ahí (?)

B: Porque es ISI, eso genera incentivo, porque tengo que publicar: (.) de alguna manera.

A: [Y] Por qué decidiste esa y no otra (.) indexada (?).

B: Ah, porque yo (.) intuí que era más fácil publicar en esa. No (?), tengo como cierta (.) percepción de dónde es más rápido publicar. (Entrevistada 11, entrevista personal, diciembre de 2017)

El fragmento expuesto permite profundizar el segundo componente, ilustrando cómo "el sistema", en tanto contexto del trabajo, no sólo es un paisaje para la actuación laboral "personal", sino que es subordinada a la acción del trabajador/a. Por ejemplo, en la cita cuando al hablante se le pregunta por qué publicó en esa revista, el responde "Porque es ISI, eso genera incentivo, porque tengo que publicar". Lo interesante es pensar que una ISI genera incentivos, y no que son los incentivos los que generan las publicaciones.

El relato conforma un juego narrativo donde se refuerza una imagen de trabajador/a que conoce domina y conoce su entorno. Un self resolutivo que puede actuar sobre su medio, guiado por sus intuiciones y percepciones (ambas habilidades personales). Esto implica que, al menos implícitamente, se trata de un yo activo, responsable de su posición social, que detenta la atribución de gobernar su espacio de trabajo. Es decir, frente a una universidad en transformación, el/la académico/a se presenta como un/a trabajador/a que conoce el escenario laboral y maneja las tácticas para desenvolverse exitosamente allí. Cabe señalar que el pool de trucos narrados se encuentra asociado a formas para 
aprovechar el contexto en favor de un proyecto personal, por ejemplo, tácticas de recuperación de autonomía o control de la carga laboral:

Yo hace como 10 años atrás, más o menos, tomé la decisión de que yo no trabajaba extra y por lo tanto yo culmino mi jornada a las 5 y media y a las 5 y media me voy, y no me lle-vo trabajo extra para la casa excepto en condiciones excepcionales. (Entrevistado 2, entrevista personal, agosto de 2019)

Una cualidad de estas tácticas es que la mayor parte de las veces son acciones emprendidas individualmente, descritas como estrategias personales o iniciativas originales de cada uno/a, descartando aspectos y condiciones sociales en las que se aprenden y desarrollan estas prácticas. Entonces, el trabajo académico es descrito como una actividad que concuerda y se ajusta a los intereses, preferencias y deseos del trabajador/a. Se trata entonces de una actividad que es construida discursivamente como si fuese una expresión singular del hiperyo. Así, emerge el/la académico/a como una figura central, un yo maximizado en sus intereses y placeres, figura solitaria sobre un fondo borroso casi ilegible que es la universidad.

\section{Narrativas identitarias del académico/a prestigioso/a}

Esta tercera narrativa congrega guiones que muestran como la distinción entre colegas y el reconocimiento son elementos centrales para la construcción de las identidades en la educación superior. Si bien el prestigio debe ser atribuido externamente, en la cultura académica es fundamental que cada miembro logre gestionarlo exitosamente para poder dar cuenta de sí en un contexto de excelencia. Esta paradoja identitaria requiere un trabajo identitario refinado dado que el/la hablante busca permanentemente corregir los posibles efectos de soberbia y el consiguiente riesgo de baja credibilidad. Las narraciones revisadas se van sofisticando para lograr el efecto de falsa modestia, en tanto presentarse a sí mismo/a, abiertamente como alguien con distinción, tiene el efecto inmediato contrario.

A partir del análisis realizado, el principal mecanismo retórico utilizado por los/as hablantes para resolver esto es acudir a los mecanismos de certificación dispuestos por los actuales sistemas gestión universitaria. Tal como señala Andrés Bernasconi (2015) la noción de académico en Chile está ligada a procesos de acreditación tales como la obtención de doctorados, la posición en rankings o la adjudicación de un fondo para la investigación. Las narrativas de académi$\mathrm{co} / \mathrm{a}$ prestigioso/a abordan justamente estas tácticas desplegadas durante las entrevistas, donde la mención de las credenciales, títulos y membresías son recursos que autorizaría una posición en la escena universitaria: "el Fondecyt en 
Chile al menos es un blindaje institucional para efecto de tus universidades, te permite ciertas libertades" (Entrevistado 12, entrevista personal, febrero 2019). Así también se ilustra en el siguiente fragmento:

Me permitió algo que se llama::: Bourdieu lo va a decir, consagración académica. Es decir que mis pares me reconocieran como investigadora y fue la primera vez que yo me nombro a mí misma como investigadora. (Entrevistada 7, entrevista personal, julio de 2019)

En este sentido, la distinción se consigue diferenciándose de otros mediante la acreditación, la cual no sólo certifica la obtención de determinados méritos, sino que permite la pertenencia a determinados grupos y autoriza el desarrollo de determinadas actividades de mayor valor. En definitiva, conseguir y otorgar credenciales sostiene un orden en torno a la asignación del prestigio y conducirá a determinadas relaciones entre académicos/as y comprensiones de sí dentro del actual escenario.

En la universidad privada ese es un te:ma cachay, cómo te valida:i, (eh::) son (.) mini acreditaciones podríamos llamarlas, porque en un sentido por ejemplo yo hice mi posgrado (.) en Chi:le: Mi doctora:do po, y:: y yo sentía que habían cosas en las que no podía participa:r. Cachay? (Entrevistada 8, entrevista personal, mayo 2018)

La distinción mediante diferentes sistemas de certificación favorece, a su vez, que los/as entrevistados/as den cuenta de su trabajo como un producto de calidad, que confirma una autoimagen positiva. Ciertamente, el juicio emitido por los diferentes sistemas de acreditación deviene conocimiento sobre sí y sobre otros/as, el cual se intensifica mediante la visibilidad y la comparación llevada a cabo por los rankings institucionales.

La estandarización de la producción académica y su comparación en diferentes rankings conforma una matriz donde el/la académico/a se lee y se ubica así mismo y compañeros de trabajo. De este modo, la narración de si mediante estas categorías ofrecidas por la nueva gestión construye posiciones en el campo laboral, estableciendo jerarquías y diseñando las relaciones entre colegas. Y desde allí la búsqueda de distinción define una posición que moldea las interacciones, las tareas, así como el valor de quien ejecuta la tarea.

Hay otra cuestión que yo creo que (.) es tan:to o más importante que es cómo cómo te ven tu pa:res y simbólicamente cómo te posiciona:i, como respecto de: de una especie de (.) de casta superio:r que será como tener (.) carga de investigación. (Entrevistada 13, entrevista personal, diciembre de 2018)

En este sentido, estar fuera de lo común (distinguido) o la competencia por lograr ello, es definido como una manera de pertenecer a la academia (De Gaule- 
jac, 2008). Así se evidencia la necesaria complicidad entre académicos y los sistemas estandarización del trabajo científico, en tanto sistemas útiles para que académicos/as dispongan de categorías para leerse a sí mismos/as, a la vez que estas les devuelven imágenes de sí, ajustadas a la gramática de la nueva universidad managerial. En ese sentido, la adscripción a los indicadores de desempeño y a los nuevos mecanismos de gestión universitaria, queda anclada a ejes identitarios como la distinción y el prestigio, referente histórico de la identidad academia (Vinck, 2014).

\section{DISCUSIONES FINALES}

Como se señaló al inicio, el análisis de 40 entrevistas permitió identificar 3 narrativas identitarias utilizadas por los académicos para dar cuenta de sí y de su trabajo en un contexto de reorganización de la educación superior. La primera narrativa se posiciona con una distancia crítica frente a las actuales formas gestión, rescatando los contenidos clásicos del oficio académico como lo son el progreso social y la formación profesional y contraponiéndolos a la cultura del accountability. La segunda narrativa devela un/a trabajador/a individual y solitario, que se despliega protagónicamente en la escena laboral, usando el contexto universitario como telón de fondo. Finalmente, la tercera narrativa muestra cómo el prestigio funciona como un elemento medular que ordena las maneras de construir y narrar las identidades académicas.

Las narrativas identificadas conforman guiones identitarios que coexisten y se entrelazan en diferentes formas y momentos, de acuerdo a las diferentes interpelaciones identitarias provenientes del escenario laboral, así como la necesidad de los/as académicos/as de responder de manera competente y pertinente a las demandas que su medio laboral les extiende. De acuerdo con Mats Alvesson y Hugh Willmott (2002) el trabajo identitario de narrarse como académico/a es una actividad lingüística dinámica, con contradicciones y permanente búsqueda de una coherencia. De allí que se torne interesante exponer al menos dos nudos críticos, donde las 3 narrativas identitarias se enlazan, convergen y exacerban, dadas las transformaciones de la educación superior: primero la ética y la intensidad laboral, y segundo, la individualización del trabajo.

En primer lugar, la ética identitaria, en tanto deber ser del trabajador/a, suele ser un punto referencial para ordenar las narraciones de trabajadores/as para dar cuenta de sí (en este caso en la academia). Toda narración identitaria devela de manera más o menos explícita una forma adecuada o valiosa de ser profesional. En el caso de la narrativa del académico/a crítico/a, se adscribe nítidamente a los códigos de la universidad burócrata, que buscan el compro- 
miso con el progreso público y el desinterés con la ambición personal, en tanto ética vocacional. Esta narrativa se construye en aparente oposición a los ideales identitarios realzados en los modelos laborales neomanageriales (la universidad actual), donde se exalta a la fuerza de trabajo por sus atributos individuales. En definitiva, se trata de una ética centrada en la consecución de metas y reconocimiento de logro personales como principio ordenador. Esto queda ilustrado en las narrativas identitarias del académico/a solitario/a y de académico/a prestigioso/a, donde se muestran como trabajadores/as que resuelven y brillan sobre una institución que sólo aparece como telón de fondo.

Aun cuando la ética identitaria se muestra divergente, al menos en la posición que se le da a la institución (para uno la universidad es central en su proyecto identitario y para el otro aparece como un telón de fondo) estas 3 narrativas desembocan en un mismo elemento central: la pasión por el trabajo como referencial identitario. La ética del compromiso justifica una intensa relación con el trabajo, conformando la base narrativa en la que se sostienen peligrosas prácticas de autointensificación y autogobierno para ser productivo/a. Es precisamente este "profesionalismo" o excesivo compromiso identitario y relacional con el progreso social y la excelencia lo que asegura que el /la académico/a siga haciendo todo lo posible por cumplir con determinadas metas en circunstancias que empeoran y dificultan trabajo. La idea de la distinción a través de la crítica y la excelencia se ve exacerbada al límite que justifica que académicos y académicas sigan trabajando en condiciones inéditas.

En segundo lugar, podemos pensar cómo las 3 narrativas presentadas se ven exacerbadas en torno a pujantes procesos de individualización. Retomando los análisis anteriores podemos señalar que, si bien la narrativa del académico/a crítico/a, con vocación y compromiso, aparenta un cierto compromiso con formas más colectivas de percibirse, también conviene preguntarse por la posición en la que se ubica dentro de la comunidad. La posición crítica implica sin duda una determinada perspectiva respecto de la sociedad. Se trata de un rol no sólo de relevancia social, sino también de una relación con la sociedad donde esta queda subordinada a una mirada experta, académica y una subalternización del otro/a. Al mismo tiempo, la identidad laboral de profesiones liberales, caracterizados por su alto nivel de preparación y autonomía, estaría directamente ligado a un signo de estatus (Dubar y Tripier, 1998; Tasset, 2016).

En este mismo sentido, la narrativa del académico/a solitario/a es evidente en su aspecto hiperindividualizado, pero la narrativa del académico/a prestigioso/a le añade un ingrediente. El espacio académico estaría conformado por identidades hiperindividualizadas, que necesitan reconocerse mediante sistemas que corroboren el mérito de cada singularidad; se trata de una pertenen- 
cia a través de la distinción. Justamente, en esa intersección, cobra sentido y utilidad los mecanismos de reconocimiento externo del desempeño y los rankings universitarios, en tanto mecanismos validados que colaboran positivamente con la autoimagen de cada académico/a y su membresía.

Así, aun cuando está ampliamente documentada la idea de que los nuevos modos de gestión universitaria desafían las identidades históricas de la academia está ampliamente documentada, este trabajo realiza un aporte novedoso al señalar que las tensiones no es lo único que ocurre. En efecto, este artículo evidencia que hay aspectos de la identidad académica que se ven profundamente exacerbados gracias a los sistemas neogerenciales. Lo señalado tiene implicancias críticas para la comunidad académica en tanto cabe señalar que hay aspectos de ella que han permitido una natural incorporación de las herramientas del management, donde cabe explicitar la coexistencia de prácticas de adhesión y resistencia a las nuevas formas de gestionar el trabajo académico.

Por último, cabe señalarse que este estudio tiene la importante limitación de no considerar la heterogeneidad de culturas académicas para los análisis de datos. Sin duda la adscripción o rechazo de la academia a las nuevas formas de management puede estar sujeta a las tradiciones particulares de cada grupo disciplinar, también a las diferentes generaciones de académicos/as, asunto que conviene revisar en futuras investigaciones.

\section{REFERENCIAS}

Ahlbäck Öberg, Shirin; Bull, Thomas; Hasselberg, Yiva \& Stenlås, Niklas (2016). Professions under siege. Statsvetenskaplig Tidskrift, 118(1), 93-126.

Ainsworth, Susan \& Hardy, Cynthia (2008). The enterprising self: An unsuitable job for an older worker. Organization, 15(3), 389-405.

https://doi.org/10.1177/1350508408088536

Altbach, Philip G. (Ed.). (2000). The changing academic workplace: Comparative perspectives. Boston College Center for International Higher Education.

Altbach, Philip \& Salmi, Jamil. (2011). The Road to Academic Excellence. The World Bank.

Alvesson, Mats \& Willmott, Hugh (2002). Identity regulation as organizational control: Producing the appropriate individual. Journal of management studies, 39(5), 619644.

Anderson, Gina (2008). Mapping Academic Resistance in the managerial University. Organization, 15(2), 251-270. https://doi.org/10.1177/1350508407086583

Araujo, Kathya \& Martuccelli, Danilo (2010). La individuación y el trabajo de los individuos. Educacao e pesquisa, 36(spe), 77-91. 
Atkinson, Paul \& Coffey, Amanda (2003). Revisiting the relationship between participant observation and interviewing. En Jaber Holstein \& James Gubrium, Inside interviewing: New lenses, new concerns (pp. 415-428). Sage.

Bejerot, Eva \& Hasselbladh, Hans (2013). Forms of intervention in public sector organizations: Generic traits in public sector reforms. Organization Studies, 34, 13571380. https: / / doi.org/10.1177/0170840613477639

Bernasconi, Andrés (2010). The Apotheosis of the Researcher and the Institutionalization of the Academic Profession in Chile. ESE-Estudios sobre Educación, 19, 139-163.

Bernasconi, Andrés (2015). La Educación Superior de Chile.Transformación, Desarrollo y Crisis. Ediciones Universidad Católica de Chile.

Braverman, Harry. (1984). Trabajo y capital monopolista. Nuestro Tiempo

Brunner, José Joaquín (2008). Educación superior en chile:instituciones, mercados y políticas gubernamentales. Leiden.

Brunner, José Joaquín \& Villalobos, Cristobal (2014). Políticas de Educación Superior en Iberoamérica, 2009-2013. Ediciones Diego Portales.

Clarke, Caroline; Knights, David \& Jarvis, Carol (2012). Labour of Love? Academics in Business Schools. Scamdinavian Journal of Managment, 28(1), 5-15. https://doi.org/10.1016/j.scaman.2011.12.003

De Gaulejac, Vincent (2008, 28 de Octubre). El costo de la excelencia. (Conferencia dictada en Buenos Aires). Buenos Aires.

Denzin, Norman (2001). Interpretive interactionism (Vol. 16). Sage.

Du Gay, Paul (2007). Organizing identity: Persons and organizations after theory. Sage.

Dubar, Claude (2000). La crise del identités, l'interpretation d'une mutation. Presses Universitaires de France.

Dubar, Claude \& Tripier, Pierre (1998). Sociologie des professions. Armand Colin.

Evetts, Julia (2011). A new professionalism? Challenges and opportunities. Current sociology, 59(4), 406-422. https://doi.org/10.1177/0011392111402585

Fardella, Carla; Sisto Vicente \& Jimenez, Felipe (2015). Nosotros los académicos: Narrativas identitarias y autodefinición en la universidad actual. Universitas psychologica, 14(5), 1625-1636. http://dx.doi.org/10.11144/Javeriana.upsy14-5.nani

Fardella, Carla; Sisto, Vicente \& Jimenez, Felipe (2017). La transformación de la universidad y los dispositivos de cuantificación. Estudos de psicología (Campinas), 34(3), 435-448. https: // doi.org/10.1590/1982-02752017000300011

Flick, Uwe (2004). Introducción a la investigación cualitativa (1 ${ }^{a}$ ed.). Morata.

Gibbons, Michael; Limoges, Camille; Nowotny, Helga; Schwartzman, Simon; Scott, Peter \& Trow, Martin (1994). The new production of knowledge: The dynamics of science and research in contemporary societies. Sage.

Gill, Rosalind (2009). Breaking the silence. the hidden injuries of neo-liberal academia. En Roisin Flood \& Rosalind Gill (Eds.), Secrecy and silence in the research process: Feminist Reflections (pp. 228-244). Routledge. 
Gorman, Elizabeth (2014). Professional Self-regulation in North America: The Cases of Law and Accounting. Sociology Compass, 8(5), 491-508.

https://doi.org/10.1111/soc4.12152

Harding, Nancy; Ford, Jackie \& Gough, Brendan (2010). Accounting for ourselves: Are academics exploited workers? Critical Perspectives on Accounting, 21, 159-168. https://doi.org/10.1016/j.cpa.2009.08.008

Holstein, Jaber \& Gubrium, James (1995). The active interview (Vol. 37). Sage.

Hood, Christopher (1991). A Public Management for all season? Public Administration, 69, 3-19.

Hualde, Alfredo (2000). La sociología de las profesiones: asignatura pendiente en América Latina. En Enrique De la Garza (Coord.), Tratado Latinoamericano de Sociología del Trabajo (pp. 664-682). El Colegio de México /FLACSO/UAM/FCE.

Merton, Robert (1968). Social theory and social structure. Free Press.

OCDE/CEPAL/CAF, (2013) Perspectivas económicas de América Latina 2014. Logística y competitividad para el desarrollo. http://www.cepal.org/es/publicaciones/1504perspectivas-economicas-america-latina-2014-logistica-competitividad-desarrollo

Potter, Jonathan (1998). Discursive social psychology: From attitudes to evaluative practices. European review of social psychology, 9(1), 233-266.

Potter, Jonathan \& Wetherell, Margaret. (1987). Discourse and Social Psychology. Sage.

Sisto, Vicente \& Fardella, Carla (2009). Control narrativo y gubernamentalidad: La producción de coherencia en las narrativas identitarias. El caso de profesionales chilenos adultos jóvenes en condiciones de vinculación laboral flexible [70 párrafos]. Forum Qualitative Sozialforschung / Forum: Qualitative Social Research, 10(2), Art. 29. https://nbn-resolving.org/urn:nbn:de:0114-fas0902292

Slaughter, Sheila \& Rhoades, Gary (2004). Academic Capitalism and the New Economy: Markets, State, and Higher Education. Johns Hopkins University Press.

Soto, Álvaro (2008). Flexibilidad laboral y subjetividades. LOM.

Soto, Álvaro \& Gaete, Tomás. (2013). Tensiones en la construcción identitaria individualizada en el trabajo flexible. Universitas Psychologica, 12(4), https://doi.org/1169-1182. 10.11144/Javeriana.UPSY12-4

Soto, Álvaro; Fardella, Carla; Valenzuela, Alan \& Carvajal, Francisca (2017). Las funciones performativas de los instrumentos en las Redes de Acción Pública. Psicoperspectivas, 16(3), 76-86. http://dx.doi.org/10.5027/psicoperspectivas-vol16-issue3fulltext-999

Stecher, Antonio (2014). Fairclough y el lenguaje en el Nuevo Capitalismo: Análisis de las dimensiones discursivas del mundo del trabajo. Psicoperspectivas, 13(3), 19-29. https:// doi.org/10.5027/PSICOPERSPECTIVAS-VOL13-ISSUE3-FULLTEXT-526

Tasset, Cyprien (2016). Génesis y realidad del precariado. Arxius, 61-72.

Trow, Martin (1993). Managerialism and the academic profession: the case of England. Studies of higher education and research, 4, 38-39. 
Vinck, Dominique (2014). Ciencias y Sociedad: Sociología del trabajo científico. Gedisa.

Watson, Tony (2009). Narrative, life story and manager identity: A case study in autobiographical identity work. Human relations, 62(3), 425-452. https: / /doi.org/10.1177/0018726708101044

Wetherell, Margaret (2007). A step too far: Discursive psychology, linguistic ethnography and questions of identity. Journal of Sociolinguistics, 11(5), 661-681. https://doi.org/10.1111/j.1467-9841.2007.00345.x

Wetherell, Margaret \& Potter, Jonathan (1998). Discourse and Social PsychologySilencing Binaries. Theory \& Psychology, 8(3), 377-388.

Wilson, Tom (1991). The proletarianisation of academic labour. Industrial Relations Journal, 22(4), 250-262.

Worthington, Frank, \& Hodgson, Julia (2005). Academic labour and the politics of quality in higher education: a critical evaluation of the conditions of possibility of resistance. Critical Quarterly, 47(1-2), 96-110.

\section{Carla FardelLa Cisternas}

Doctora en Psicología Social de la Universidad Autónoma de Barcelona. Investigadora de la Facultad de Educación y Ciencias Sociales, Universidad Andrés Bello. Su investigación se orienta al análisis de políticas públicas para la ciencia y al desarrollo de metodologías cualitativas para el estudio de diferentes áreas de la psicología social.

carla.fardella@unab.cl

https://orcid.org/0000-0001-8936-2435

\section{JAVIERA GARCÍA-MENESES}

Psicóloga y Candidata a Doctora en Psicología de la Pontificia Universidad Católica de Valparaíso. Personal técnico y tesista doctoral de los proyectos Fondecyt (1180129-1160650). Su investigación se orienta al estudio de los afectos como elementos constitutivos de la subjetividad laboral de trabajadores.

javiera.garcia.m@mail.pucv.cl https://orcid.org/0000-0002-4470-4427 


\section{ÁLVARO SOTO ROY}

Psicólogo, Doctor en Ciencias Sociales orientación Ciencias del Trabajo de la Pontificia Universidad Católica de Lovaina. Investigador Asociado del Centro Núcleo Milenio Autoridad y Asimetrías de Poder. Investiga las relaciones entre las dimensiones estructurales del trabajo y procesos subjetivos.

asoto@uahurtado.cl https://orcid.org/0000-0003-4551-530X

\section{ALEJANDRA CORVALÁN-NAVIA}

Psicóloga Universidad de Valparaíso, Máster Análisis y Conducción de Grupos, Universidad de Barcelona y Candidata a Doctora Programa Educación y Sociedad, Universidad Andrés Bello. Tesista proyecto Fondecyt (1180129). Su interés investigativo es la construcción identitaria de académicos/as en contextos de trabajo científico. alejandracorvalan@gmail.com

https://orcid.org/0000-0002-6329-403X

\section{AGRADECIMIENTOS}

FONDECYT Regular 1180129 "El trabajo científico en Chile"; Programa de Investigación Asociativa (PIA) SOC180039 y Centro Núcleo Milenio Autoridad y Asimetrías de Poder NCS17_007.

\section{FORMATO DE CITACIÓN}

Fardella Cisternas, Carla; García-Meneses, Javiera; Soto Roy, Álvaro \& CorvalánNavia, Alejandra (2021). Exacerbados. Identidades académicas y la transformación de la educación superior chilena. Quaderns de Psicologia, 23(2), e1602.

https: / / doi.org/10.5565/rev/qpsicologia. 1602

HISTORIA EDITORIAL

Recibido: 18-01-2020

$1^{\mathrm{a}}$ revisión: $16-11-2020$

Aceptado: 07-05-2021

Publicado: $31-08-2021$ 